\title{
Liquid stool incontinence with severe urgency: anorectal function and effective biofeedback
} treatment

\author{
G Chiarioni, C Scattolini, F Bonfante, I Vantini
}

\begin{abstract}
The motor and sensory function of the anorectum is well characterised in patients with solid stool incontinence. Fewer data are available in the case of liquid stool incontinence. Anorectal sensorimotor function was studied in 16 patients with liquid stool incontinence and severe urgency (10 with diarrhoea) unresponsive to conventional medical treatment, and in $\mathbf{1 6}$ healthy volunteers. The only significant difference found between incontinent patients and controls was a reduction in squeeze duration $(\mathbf{p}<\mathbf{0 . 0 0 0 1})$. Fourteen patients were selected to receive biofeedback treatment. Treatment was associated with a substantial improvement in continence in $\mathbf{1 2}$ patients and with a significant decrease in urgency $(p<0.05)$. Bowel frequency was not significantly influenced. Most patients showed a persistent improvement in anal motor function. Functional parameters were not predictive of outcome of treatment; the poor responders showed major psychological problems. In conclusion, an anal motor deficit is often present in disabling liquid stool incontinence. Biofeedback may improve anal continence in $75 \%$ of patients.
\end{abstract}

(Gut 1993; 34: 1576-1580)

Faecal incontinence is a disabling condition, which is reported to have a population prevalence in the range of $0 \cdot 1 \%$ to $1.5 \% .^{1}$ It is probably greatly under-reported by patients, because of the embarrassment it causes. Most studies on anorectal function have focused so far on solid stool incontinence, which is probably the worse form. Until a few years ago this was the uncontested domain of surgeons because of the poor results of pharmacological treatment. More recently, biofeedback treatment has been suggested and reported to be effective in about two thirds of patients. ${ }^{23}$ It is based on the rationale that patients can be trained to increase the anal sphincter contractile capability in response to rectal distension, if a residual rectal sensation is present. ${ }^{2}$ Liquid stool incontinence has so far received little attention. Its incidence in the general population is not clearly established, but it is unlikely to be negligible. In a recent study as many as $5 \%$ of subjects in a group of students and hospital employees were reported as losing bowel control, at least occasionally. ${ }^{4}$ Incontinence, however, was poorly defined (for solid or liquid stools), but we may reasonably suppose that in many cases it was for liquid stools only. The same study suggested that faecal soiling may prompt people with bowel dysfunction to go and see the doctor. ${ }^{4}$

A common clinical finding is occurrence of liquid stool incontinence together with severe urgency. ${ }^{5}$ This combination of symptoms may be unresponsive to conventional medical treatment. In addition, the role of biofeedback treatment in these conditions is still unclear, ${ }^{6}$ and the efficacy of retraining in liquid stool incontinence has been questioned in a recent study. ${ }^{7}$ This study was designed to evaluate anorectal sensorimotor function and the effectiveness of biofeedback treatment in a group of patients complaining of liquid stool incontinence and severe urgency resistant to conventional medicine treatments.

\section{Patients and methods}

PATIENTS

Twenty two patients referred for liquid stool incontinence were considered. Each patient was provided with a diary card to record bowel frequency and episodes of incontinence and urgency over a one month period. Criteria for inclusion were: liquid stool incontinence for at least 12 months, frequency of incontinence of at least once a week, frequent severe urgency, and inefficacy of conventional medical treatment (constipating agents, fibre supplementation, regular enemas) given for at least one month by the referring physician. Severe urgency was defined as an urgent need to defecate which has to be relieved in less than one minute to avoid incontinence. Only the patients meeting all the above mentioned criteria were included in the study. They were 16 subjects ( 11 women and five men) aged from 24 to 75 years (mean 49). The other patients were excluded for lower frequency of incontinence (three patients) or absence of severe urgency (three patients). All the patients included signed an informed consent form. Frequency of liquid stool incontinence ranged from three times a day to once a week (mean 0.92 episodes/day). Twelve patients also complained of diarrhoea defined either as frequent passage of small amounts of stools or as habitual passage of liquid or semiliquid stools. Mean bowel frequency in the group was 3/day (SEM $0 \cdot 7$ ). We did not attempt any better characterisation of this symptom because this may be difficult in patients with incontinence. ${ }^{8}$ Nine patients with diarrhoea complained of incontinence in the presence of loose bowel movements only (Table I).

All patients had conventional examinations for anal incontinence or diarrhoea, or both including 
TABLE I Clinical details of patients

\begin{tabular}{llllll} 
& & & \multicolumn{2}{l}{ Episodes/day } & \\
\cline { 4 - 5 } Patient & Age/sex & Stools/day & Incontinence & Urgency & Underlying diseases \\
\hline 1 & $58 \mathrm{~F}$ & 1 & $0 \cdot 14$ & 2 & Prolapsing haemorrhoids \\
2 & $53 \mathrm{M}$ & 6 & 3 & 8 & Prolapsing haemorrhoids \\
3 & $73 \mathrm{~F}$ & 4 & 1 & 3 & Perineal descent, haemorrhoids \\
4 & $64 \mathrm{~F}$ & 1 & $0 \cdot 28^{\star}$ & 4 & IBS \\
5 & $75 \mathrm{~F}$ & 1 & $0 \cdot 42^{\star}$ & 1 & Diabetes, haemorrhoids \\
6 & $40 \mathrm{M}$ & 2 & 2 & 7 & IBS \\
7 & $31 \mathrm{~F}$ & 10 & 1 & 6 & Fistulectomy \\
8 & $24 \mathrm{M}$ & 3 & $0 \cdot 14^{\star}$ & 1 & IBS \\
9 & $29 \mathrm{~F}$ & 1 & $0 \cdot 56^{\star}$ & 2 & Haemorrhoidectomy \\
10 & $35 \mathrm{M}$ & 1 & 1 & 4 & Crohn's disease \\
11 & $67 \mathrm{~F}$ & 6 & 1 & 5 & Unknown \\
12 & $49 \mathrm{~F}$ & 3 & $0 \cdot 14^{\star}$ & 2 & IBS \\
13 & $33 \mathrm{M}$ & 3 & $0 \cdot 28^{\star}$ & 7 & IBS \\
14 & $58 \mathrm{~F}$ & 6 & $3^{\star}$ & 10 & IBS, haemorrhoids \\
15 & $39 \mathrm{~F}$ & 1 & $0 \cdot 28^{\star}$ & 3 & IBS \\
16 & $55 \mathrm{~F}$ & 2 & $0 \cdot 42^{\star}$ & 8 & Diabetes \\
\hline
\end{tabular}

IBS=irritable bowel syndrome; ${ }^{\star}$ Incontinence with loose stools only.

flexible sigmoidoscopy, barium enema, barium meal and follow through, faecal fat estimation, xylose test, glucose breath test, and lactose tolerance test. Table I shows clinical details of the incontinence study population. Irritable bowel syndrome was diagnosed in patients with normal findings, but with abdominal pain relieved by defecation and at least two further symptoms featuring among the 'Manning criteria'. The incontinence was considered idiopathic in patients in whom no underlying condition could be detected. Sixteen healthy volunteers without gastrointestinal or anorectal symptoms ( 13 women and three men, mean age 43 , range $21-72$ years) served as a control group.

\section{ANORECTAL MANOMETRY}

All subjects were studied without a bowel preparation and after conventional medical treatment had finished. With the patient lying in the left lateral position, a three balloon apparatus ${ }^{2}$ was inserted into the rectum to permit rectal distension and pressure recordings from the rectum and upper and lower anal canal. The rectal balloon, $5 \mathrm{~cm}$ in length, was positioned with its distal edge $5 \mathrm{~cm}$ from the anal verge. The balloons located in the upper and lower anal canal reflect the activity of the internal and the external sphincter, respectively. ${ }^{2}$ Each balloon was connected to an air filled pressure transducer. The electrical signals from the pressure transducers were amplified and converted to digital form by an electronic interface unit (GR 800, Aspen Medical, Dingwall, Scotland). Data

TABLE II Anorectal function in healthy controls and incontinent patients

\begin{tabular}{llc}
\hline & $\begin{array}{l}\text { Controls } \\
(n=16)\end{array}$ & $\begin{array}{l}\text { Incontinent } \\
\text { patients } \\
(n=16)\end{array}$ \\
\hline Rectal sensation (ml) & $11 \cdot 9(1)$ & $13 \cdot 1(1 \cdot 3)$ \\
Threshold for IAS relaxation (ml) & $13 \cdot 8(1 \cdot 3)$ & $17 \cdot 5(2 \cdot 3)$ \\
Threshold for EAS contraction $(\mathrm{ml})$ & $15(1 \cdot 3)$ & $19 \cdot 4(3)$ \\
Maximum voluntary contraction & $40 \cdot 8(4 \cdot 1)$ & $38 \cdot 4(3 \cdot 7)$ \\
(mm Hg) & $49 \cdot 4(1 \cdot 4)$ & $22 \cdot 4(2 \cdot 8)^{\star}$ \\
Squeeze duration (s) & $25 \cdot 6(2 \cdot 5)$ & $26 \cdot 8(2 \cdot 8)$ \\
Rectal pressure at 100 ml (mm Hg) & $287 \cdot 5(25 \cdot 6)$ & $262 \cdot 5(24 \cdot 4)$ \\
MTV (ml) & & \\
\hline IAS=internal anal sphincter; EAS=external anal sphincter; \\
MTV =maximum tolerated volume. Data expressed as mean \\
(SEM); ${ }^{\star}$ p $<0 \cdot 0001$.
\end{tabular}

were then transferred and displayed on a computer by means of specially designed software (Aspen Medical). Pressure curves were analysed manually. Rectal sensation was assessed by rapid air distension of the rectal balloon with volumes decreasing from $50 \mathrm{ml}$ to $10 \mathrm{ml}$ (in $10 \mathrm{ml}$ decrements). Placebo distensions were randomly performed throughout the procedure. The rectoanal inhibitory reflex was measured using the threshold for internal sphincter relaxation (smallest volume of rectal distension producing a relaxation of at least $3 \mathrm{~mm} \mathrm{Hg}$ ). External anal sphincter function was investigated by: (1) the threshold of external anal sphincter contraction (smallest volume of rectal distension causing a phasic sphincter contraction of at least $3 \mathrm{~mm} \mathrm{Hg}$ ), (2) maximum voluntary contraction (mean of three trials of maximum voluntary squeezing lasting for five seconds), and (3) squeeze duration (length of time during which each subject could voluntarily keep a pressure rise of $10 \mathrm{~mm} \mathrm{Hg}$ in the lower anal canal balloon, mean of three trials). Rectal compliance was evaluated by a cylindrical latex balloon (condom type), $10 \mathrm{~cm}$ in length, mounted on a stiff PVC tube measuring $0.3 \mathrm{~mm}$ in diameter. This balloon was placed in the rectum at a distance of $8 \mathrm{~cm}$ from the anal verge and connected to an air filled transducer. The balloon was inflated with air in $50 \mathrm{ml}$ increments. Inflations were separated by an adaptation interval of one minute. An inflation volume of $100 \mathrm{ml}$ was well tolerated by all subjects. The pressure at $100 \mathrm{ml}$ (corrected by subtracting the pressure within the balloon inflated in ambient air) and the maximum tolerable volume (the balloon volume causing abdominal discomfort or spontaneous expulsion) were taken as indices of rectal compliance.

\section{BIOFEEDBACK TREATMENT}

Biofeedback treatment was performed in all but two patients (patients 1 and 2, Table I), in whom all manometric results were within the normal range. Both had prolapsing external haemorrhoids and were therefore referred to a surgeon for haemorrhoidectomy; both reported regression of symptoms after surgery. Data from these two patients are included in the statistical analysis of the diagnostic anorectal manometry, as they were incontinent. Other patients had external haemorrhoids, though less serious.

Patients received a full explanation of the relevance of the external sphincter in controlling anorectal functioning before starting biofeedback. The conditioning session consisted of two treatment trials carried out within two days with the three balloon system. Patients were trained in increasing strength and duration of external anal sphincter contractions in response to rectal distension. Particular care was taken to get the patients to contract the sphincter for at least 20 seconds. This was first accomplished with the manometric apparatus in position and with the visual help of the computer screen. The same response was then produced withholding the visual display. At home, each patient was instructed to practice contracting the sphincter several times a day (at least 20 times three times 
daily) for 20-30 seconds as directed in conditioning sessions. Patients were interviewed monthly for the first five months and every three months thereafter. Meanwhile, they continued the daily recording of bowel movements and frequency of incontinence and urgency. Patients and referring physicians were instructed to avoid any change in the medical management of incontinence during the study. The compliance to this advice was checked at each interview. After one month, another training session was provided, if needed. All treatment sessions were conducted by one of the authors (GC). A good response to treatment was defined as restoration of continence or a decrease of at least $75 \%$ in frequency of incontinence. ${ }^{3}$ Statistical analysis of the data was done using the Student's $t$ test for paired data or the Wilcoxon rank sum test for paired data, as indicated. Data are expressed as mean (SEM).

\section{Results}

\section{ANORECTAL FUNCTION}

Rectal sensation was within the range of our control group $(\leqslant 20 \mathrm{ml})$ in all incontinent patients. There was no significant difference in threshold of internal anal sphincter relaxation between controls and incontinent patients with only three patients showing values outside the control range $(\leqslant 20 \mathrm{ml})$. The threshold of external anal sphincter contraction was the same in incontinent patients and in controls (Table II) and only three patients showed a value above the upper limit of normal ( $20 \mathrm{ml}$ of air). Mean amplitude of maximum voluntary contraction was similar in incontinent patients and controls (38 $v 41 \mathrm{~mm} \mathrm{Hg}$, Table II). On the other hand, squeeze duration in incontinent subjects was significantly shorter than in healthy volunteers $(22.4(2.9) v 49.4(1.4) \mathrm{sec}, \mathrm{p}<0.0001)$. Squeeze duration was less than 35 seconds (lower normal limit) in all patients except the two with prolapsing haemorrhoids. Figure 1 shows the most common pattern of prolonged contraction seen in patients with incontinence - that is, a strong initial sphincter contraction followed by rapid relaxation. No statistical differences were found between incontinent patients and controls with regard to rectal compliance, whether as maximum tolerable volume or as intrarectal pressure at $100 \mathrm{ml}$ of air (Table II).

\section{BIOFEEDBACK TREATMENT}

Bowel frequency and frequency of incontinence and urgency were assessed by reviewing the diary cards. The first session of biofeedback conditioning was associated with an improvement in external anal sphincter function in all subjects. The threshold of phasic sphincter contraction reverted to normal in the three patients with abnormal values. After retraining, squeeze duration increased significantly from $19 \cdot 6(2 \cdot 4)$ to $38.3(3.2)$ seconds $(p<0.0001)$ with all patients gaining a squeeze duration of at least 20 seconds (Fig 2). At the first interview, 11 patients reported a substantial improvement in faecal continence (good responders according to our criteria). Two other patients reported a slight
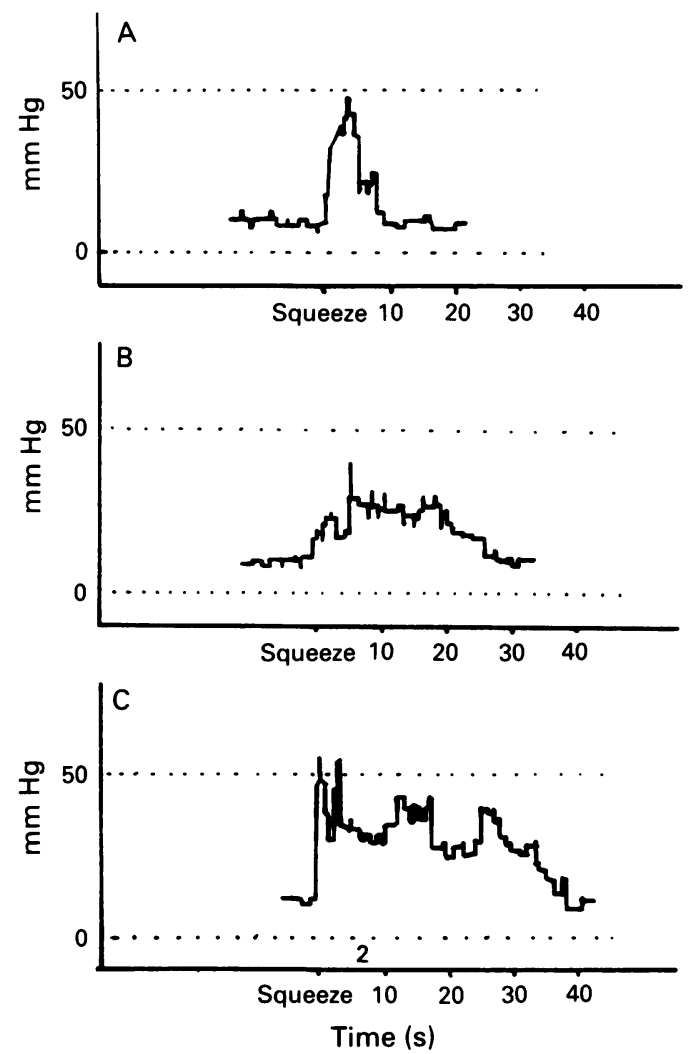

Figure 1: (A) Manometric tracing from an incontinent patien (case 6) showing an easily fatiguing anal sphincter on an attempt of prolonged squeezing; $(B)$ tracing from the same patient showing increased squeeze duration, after retraining; (C) tracing of a prolonged voluntary contraction from a healthy volunteer.

improvement, and one reported no improvement at all. After additional training, another subject was classified as a good responder, while two showed a persistently poor response. The overall success rate was $85 \%$ of treated patients (75\% of all incontinent subjects). Restoration of continence was evident in nine patients, while three patients showed a reduction in frequency of incontinence ranging from $75 \%$ to $90 \%$. With

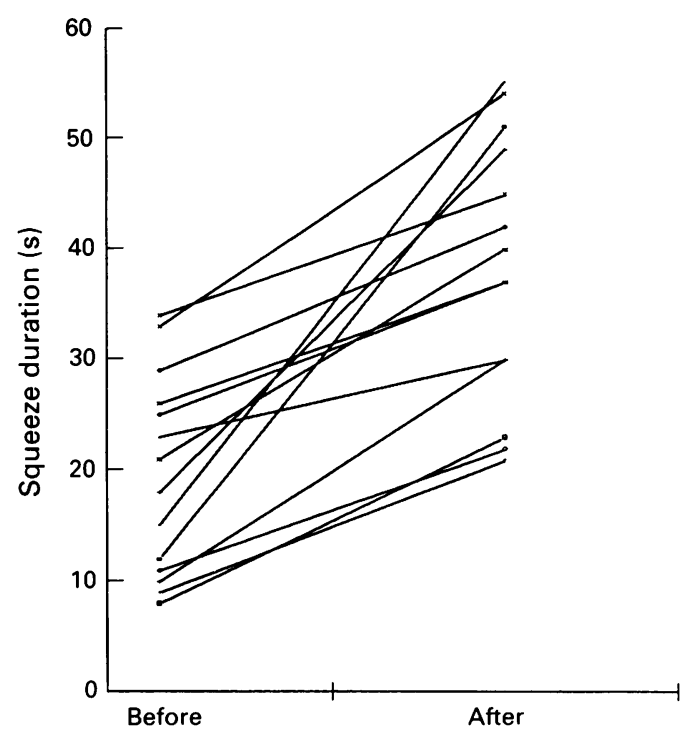

Figure 2: Squeeze duration in 14 patients with liquid stool incontinence before and after retraining. There was significant improvement in squeeze duration after biofeedback treatment $(p<0.0001)$. 
a more in depth analysis of results, restoration of continence was seen only in patients achieving a squeeze duration over 30 seconds. No patient reported a change of medical treatment during the study. After the first interview 10 patients (seven good responders, three poor responders) had a second diagnostic anorectal manometry. The good responders showed a persistent improvement in external anal sphincter function, while in the poor responders it had reverted to prebiofeedback values. The two patients who did not respond to retraining refused to have a second training sessions and were lost to follow up, after three months. These were irritable bowel syndrome patients (patients 13 and 15, Table I) with major psychological problems. At diagnostic anorectal manometry, they showed an isolated alteration of squeeze duration without any impairment of internal anal sphincter function. In the good responder group, the improvement in continence was maintained throughout our follow up period (mean 14.5 months, range 3-21).

After biofeedback, the frequency of episodes of severe urgency was significantly decreased compared with the month before treatment $(1.9$ $(0.4) v 4.5(0.7)$ episodes/day, $\mathrm{p}<0.05)$. Bowel frequency was also decreased $(2.4(0.5) v 3 \cdot 1$ $(0.7)$ bowel movements/day), but the difference did not reach statistical significance $(p=0 \cdot 06)$. Six patients still complained of loose motions. After three months of retraining, good responders were questioned about the social impact of the treatment. They were pleased with the results and reported an increase in their social activities.

\section{Discussion}

A motor deficit of the external anal sphincter was seen in most of our patients with liquid stool incontinence and severe urgency. The relevance of impaired function of the external anal sphincter in liquid stool incontinence has been suggested in previous studies ${ }^{10}$ and is confirmed by our data. The most common abnormality in our patients was isolated impairment of prolonged squeezing. Prolonged contraction of the external anal sphincter is not often evaluated in faecal incontinence. ${ }^{11-13}$ This may explain the finding of normal anal motor function in many incontinent patients. ${ }^{1213}$ Whitehead et al, using the same balloon probe as in our study, showed that the external anal sphincter fatigues in less than 30 seconds in geriatric patients with solid stool incontinence. ${ }^{14}$ On the other hand, patients complaining of chronic diarrhoea and faecal incontinence had squeeze duration values similar to healthy volunteers, measured with perfused catheters. ${ }^{15}$ Different techniques, reference values $(5 \mathrm{~mm} \mathrm{Hg}$ over anal basal pressure to define prolonged squeezing), and patient selection criteria may account for the discrepancy vis a vis our results. An easily fatiguing sphincter may explain the severe urgency reported by our patients. On presentation of faeces to the proximal anal canal, the duration of the squeezing effort may not be sufficient for rectal adaptation. As a consequence, patients may feel a profound anorectal discomfort and have minor leaking.
The noted decrease in urgency after retraining may be consistent with this hypothesis. The clinical significance of the motor abnormality is also confirmed by the fact that rectal sensation and the rectoanal inhibitory reflex were not significantly changed in our patients. Both parameters have been found to be grossly impaired in subgroups of faecally incontinent patients. ${ }^{16} 17$

We did not study anal basal pressure, which is commonly believed to play a significant part in preserving faecal continence for liquids. ${ }^{6}$ Our balloon probe is not suitable for this, but anal basal pressure would not seem to influence the outcome of patients receiving biofeedback treatment. ${ }^{18}$ Training was associated with normalisation of external anal sphincter phasic contraction and with an increase in squeeze duration in all patients. The motor function of the sphincter seemed to be persistently improved in patients regaining continence, but not in poor responders ( $71 \%$ of patients tested after training). Improved sphincter function was often achieved after only one retraining session and was associated with a significant, longlasting clinical benefit in $85 \%$ of patients treated. The patients not only showed an improved continence mechanism, but also reported a significant decrease in urgency. Bowel frequency, on the other hand, was only slightly modified. Some patients may have recorded an episode of faecal incontinence as a bowel movement, before the beginning of retraining. ${ }^{8}$ In any event, improved faecal continence was unlikely to be related to changes in bowel habits because many patients continued to report loose bowel movements.

It is unclear why some patients apparently lose the improvement in motor function gained during biofeedback sessions. We were unable to predict the outcome of treatment on the basis of functional parameters, thus confirming the finding of previous studies. ${ }^{3}$ The two poor responders in our group were both irritable bowel syndrome patients with major psychological problems. They seemed to be particularly concerned about their incontinence, and this factor was thought to play an important part in their psychosocial dysfunction by the referring physician. The reverse could also be true, and mental state was actually the only variable which differentiated these patients from irritable bowel syndrome patients who responded satisfactorily to treatment. Our data confirm the impression gained from previous studies that psychological factors may affect the outcome of retraining treatment. $^{19}$

One might argue that spontaneous remission may have occurred in our patients. Two recent controlled studies of biofeedback treatment $v$ conventional medical treatment have cast doubts on the effectiveness of retraining, particularly in liquid stool incontinence in diarrhoea. ${ }^{72}$ Spontaneous regression of faecal incontinence in our patients is unlikely because of the duration of symptoms before biofeedback and the close time relation between treatment and improvement. We elected to study only patients with disabling liquid stool incontinence and urgency where conventional medical treatment had already failed. Our study population may have been different from that examined in other studies in 
respect of different bowel habits (less consistent diarrhoea in our patients). In addition, measurements of prolonged squeezing were not recorded in the two studies where biofeedback was reported to be as effective as conventional medical treatment. Failure to maintain prolonged voluntary anal contraction seems to be critical in our patients. As a matter of fact, a clinical benefit was seen even with an occasionally decreased amplitude in external sphincter contraction when improvement in squeeze duration was achieved (Fig 1). Furthermore, the clinical outcome seemed also to be related to the length of prolonged voluntary anal contraction achieved by patients. MacLeod reported effective biofeedback treatment with patients contracting the anal sphincter for 20-30 seconds. ${ }^{21}$ Similarly, Miner, in a successful controlled biofeedback trial, encouraged patients to squeeze for at least 20 seconds. ${ }^{18} \mathrm{~A}$ good response to training was associated with improved squeeze duration in our patients, but increased confidence in mastering anorectal function may also have been of some benefit.

In conclusion, a motor deficit of the anal sphincter is evident in most patients complaining of liquid stool incontinence associated with severe urgency and unresponsive to conventional medical treatment. This consists more often than not in impairment of prolonged voluntary anal contraction. This should be carefully looked for because it can be improved by biofeedback treatment. In this group of patients, biofeedback treatment is effective in restoring socially acceptable faecal continence in $75 \%$ of cases, even in the presence of diarrhoeal stools. In such patients, this type of treatment may be regarded as being quick, safe, comparatively simple, and inexpensive.

We wish to thank Professor Anthony Steele for reviewing the English form of the manuscript.
1 Whitehead WE, Schuster MM. Fecal incontinence. In: Surwit RS, Williams RB Jr, Shapiro D, eds. Gastrointestinal disorders: behavioral and physiological basis for treatment. Orlando: Academic Press, 1985: 229-75.

2 Cerulli MA, Nikoomanesh P, Schuster MM. Progress in biofeedback conditioning for fecal incontinence. Gastrobioteedback conditioning $1979 ; 76: 742-6$.
enterog

3 Wald A. Biofeedback therapy for fecal incontinence. Ann Intern Med 1981; 95: 146-9.

4 Drossman DA, Sandler RS, Broom CM, McKee DC. Urgency and fecal soiling in people with bowel dysfunction. Dig Dis Sci 1986; 31: 1221-5.

5 Read M, Read NW, Barber DC. Duthie HL. Effect of loperamide on anal sphincter function in patients complaining of chronic diarrhoea with fecal incontinence and urgency. Dig Dis Sci 1982; 27: 807-14.

6 Schiller LR. Fecal incontinence. In: Sleisenger MH, Fordtran JS, eds. Gastrointestinal disease pathophysiology diagnosis management. Philadelphia: WB Saunders, 1989: 317-31.

7 Loening-Baucke V. Efficacy of biofeedback training in improving faecal incontinence and anorectal physiologic improving faecal incontinence and

8 Leigh RJ, Turnberg LA. Faecal incontinence: the unvoiced symptom. Lancet 1982; i: 1349-51.

9 Manning AP, Thompson WG, Heaton KW, Morris AF Towards positive diagnosis of the irritable bowel. $B M \dot{F}$ $1978 ; 2: 653-4$.

10 MacLeod JH. Biofeedback in the management of partial anal incontinence. Dis Colon Rectum 1983; 26: 244-6.

11 Schiller LR, Santa Ana CA, Schmulen AC, Hendler RS, Harford WV, Fordtran JS. Pathogenesis of fecal incontinence in diabetes mellitus evidence for internal-analsphincter dysfunction. $N$ Engl F Med 1982; 307: 1666-71.

12 McHugh SM, Diamant NE. Effect of age, gender, and parity on anal canal pressures: contribution of impaired anal sphincter function to fecal incontinence. Dig Dis Sci 1987; 32: 726-36.

13 Allen ML, Orr WC, Robinson MG. Anorectal functioning in fecal incontinence. Dig Dis Sci 1988; 33: 36-40.

14 Whitehead WE, Burgio KL, Engel BT. Biofeedback treatment of fecal incontinence in geriatric patients. $\mathcal{F}$ Am Geriatr Soc 1985; 33: 320-4.

15 Read NW, Harford WV, Schmulen AC, Read MG, Santa Ana CA, Fordtran JS. A clinical study of patients with fecal incontinence and diarrhoea. Gastroenterology 1979; 76: 747-56.

16 Sun WM, Read NW, Donnelly TC. Impaired internal anal sphincter in a subgroup of patients with idiopathic fecal incontinence. Gastroenterology 1989; 97: 130-5.

17 Lubowski DZ, Nicholls RJ. Faecal incontinence associated with reduced pelvic sensation. Brf Surg 1988; 75: 1086-8.

18 Miner PB, Donnelly TC, Read NW. Investigation of mode of action of biofeedback in treatment of fecal incontinence. Dig Dis Sci 1990; 35: 1291-8.

19 Orne MT. The efficacy of biofeedback therapy. Annu Rev Med 1979; 30: 489-503.

20 McHugh SM, Walma K, Diamant NE. Fecal incontinence: a controlled trial of biofeedback [Abstract]. Gastroenterology 1986; 90: 1545

21 MacLeod JH. Management of anal incontinence by biofeedback. Gastroenterology 1987; 93: 291-4. 